University of Wollongong

Research Online

Faculty of Arts - Papers (Archive)

Faculty of Arts, Social Sciences \& Humanities

$1-1-2011$

\title{
Halliday's model of register revisited and explored
}

Annabelle Lukin

Macquarie University, Australia

Alison R. Moore

University of Wollongong, amoore@uow.edu.au

Maria Herke

Macquarie University

Rebekah Wegener

Macquarie University

Canzhong Wu

Macquarie University

Follow this and additional works at: https://ro.uow.edu.au/artspapers

Part of the Arts and Humanities Commons, and the Social and Behavioral Sciences Commons

\section{Recommended Citation}

Lukin, Annabelle; Moore, Alison R.; Herke, Maria; Wegener, Rebekah; and Wu, Canzhong, Halliday's model of register revisited and explored 2011, 187-213.

https://ro.uow.edu.au/artspapers/614

Research Online is the open access institutional repository for the University of Wollongong. For further information contact the UOW Library: research-pubs@uow.edu.au 


\title{
Halliday's model of register revisited and explored
}

\author{
Annabelle Lukin, Alison Moore, Maria Herke, \\ Rebekah Wegener and Canzhong Wu
}

\begin{abstract}
Halliday's description of register as 'a variety of language, corresponding to a variety of situation', with situation interpreted 'by means of a conceptual framework using the terms "field", "tenor" and "mode" (Halliday, 1985/89: 29, 38) is revisited to reflect on the theoretical work the term 'register' does within the SFL paradigm. In doing so, we recognize that the concepts of a linguistic theory are 'ineffable' (Halliday, 2002 [1988]); i.e. that 'providing definitions of a theoretical term ... requires that it be positioned vis-à-vis other concepts in the theory' (Hasan, 2004: 16). It follows that changing the position of 'register' in the theory changes the nature of the concept. So while alternative uses of the term 'register' - such as in Martin's genre model (e.g. 1992) and Halliday's model - may advance a shared programme for language description and explanation as a route to social change, they must be seen as more than terminological variants. One consequence of the productivity of Martin's approach has been that the Hallidayan line of register theory has not had sufficient critical explication. This paper therefore begins with a brief review of the register concept. It then exemplifies the term, as postulated by Halliday, with a registerial analysis of surgical interaction, drawing on Hasan's context modelling (e.g. Hasan 1995, 2004, 2009a), and adopting what Matthiessen (1993) calls a 'metafunctional slice' with 'multistratal coverage'. By accounting for choice at different strata, we seek to 'relate wording to context via meaning which acts as the interface between the two' (Hasan 2009a: 182).
\end{abstract}

KEYWORDS: REGISTER; CONTEXT; SYSTEMIC FUNCTIONAL LINGUISTICS; MEDICAL DISCOURSE; PROBABILISTIC MODELLING

\footnotetext{
$\overline{\text { Affiliation }}$

Centre for Language in Social Life, Macquarie University, Australia. email: annabelle.lukin@ling.mq.edu.au (corresponding author)
} 


\section{Introduction}

The concept of register is central to Halliday's model of language. It is central not only in the sense of being important to the theory, but central also in the sense of 'at the centre of' the theory. The case we make here is that register holds the dimensions of Halliday's systemic functional theory together, and we begin the paper by exploring the place of register with respect to Halliday's dimensions. In doing so, we recognize that defining a theoretical term, as Hasan argues, 'requires that it be positioned vis-à-vis other concepts in the theory' (Hasan, 2004: 16). In other words, the concepts are 'ineffable' (Halliday, 2002 [1988]). Since Halliday has made the case that language is multidimensional (e.g. Halliday, 2003), to understand 'register' in Halliday's terms is to understand its relationship to such dimensions.

Our starting point might initially strike the reader as a well worn path. Matthiessen's 1993 paper 'Register in the round', for instance, addressed the notion of register from a similar perspective. His paper, now nearly 20 years old, called for different standpoints on the description of register, as a means of bringing theory and description together. These standpoints were derived from the basic principles of Halliday's theory of language, which we discuss below. Matthiessen's paper provided a list of 'register' descriptions, the wording of which Matthiessen described as 'fairly non-technical'. His list includes 'the language of exposition', 'the language of geography', 'the language of casual dinner table conversation', 'the language of news reporting,' 'the language of business communication', etc. As Matthiessen (1993: 274) wrote at the time:

It would be an important contribution to describe the overall semiotic space in which these 'registers' are located relative to one another - to provide a general account of field, tenor and mode and to specify the values for each variety listed above. This would introduce greater precision in register analysis and might very well invite us to re-interpret some of the varieties that have been identified in the past. As already noted, there is a certain danger that we simply take over categories based on folk genres.

There are surprisingly few instances of the kind of work Matthiessen was calling for in his paper, i.e. descriptive work genuinely based in the notion of register as elaborated by Halliday. (Matthiessen et al., 2005 is one such instance; Hasan's work on context (e.g. Hasan, 1985/89, 1995, 1999), text structure and texture (e.g. Hasan, 1985/89) and semantics (e.g. Hasan, 2009b) has presupposed Halliday's model.) The success of Martin's model (see Martin, 2009 for an inventory of this genre research) has meant, to some degree, an obscuring of the theoretical distinction between Halliday's notion of register, and Martin's use of his own terms 'genre' and 'register.' In our view this is one the reason for a relative lack of critical explication and application of register along Halliday's line of development. 
In this paper we do not want to detract from the achievements of distinct approaches in SFL, nor do we want to reiterate all the differences in approach themselves. We do however want to motivate the need to make what might otherwise seem like either uncontentious or over-vehement claims. It is not that one must take Halliday's view but it is important that one continue to engage with it, given that Halliday himself continues to hold it. In the section below, we briefly outline our perspective of Halliday's view. Since our aim is to move on to demonstrate 'register alone' (Martin, 1999), the reader is directed to Martin (1999) and Hasan (1995) for focused accounts of the different genre and register concepts and their implications for SFL. Hasan concludes her paper on these topics as follows:

My own view is that the stratification of genre and register [as posited by Martin and colleagues], the collapsing of the social and the verbal, at both these planes, which in turn entails a questionable view of language, has a highly deleterious effect: It moves the whole issue of text structure and its activation from active, feeling, reacting participants co-engaged in some interaction to given forms of talk that represent the ways things are done in our culture, as if the culture is unchanging and as if the participants are simply pre-programmed. (Hasan, 1995: 283)

In a sense we are largely programmed by our societies into given ways of doing culture. But societies and cultures change. Halliday's model of language, as set out in Figure 1, shows the openness of language to the eco-social environment, and, therefore, to the dynamics of social change. Halliday's notion of register is, in our view, particularly well geared to describing language variation and consistency without making such language variation isomorphic with social variation. As a central conceptual tool that does not stratify the relation of genre and register, Halliday's notion of register helps us recognize - or at least frame and test - the idea that recognized social situations might sometimes be the same register, or identify and evaluate the register differences in what are normally counted as 'the same' social activities: it is a model well suited to calibrating the shuffling and reshuffling of cultural space-time and its boundaries.

Our paper therefore now turns to (a) our brief review of Halliday's register concept and how its central place in the theory gives it its descriptive power; and (b) an exemplification of Halliday's concept, by way of a registerial analysis that draws on Hasan's parametric approach to context modelling (e.g. Hasan 1995, 1999, 2004, 2009a; Butt, 2003) and Matthiessen's 'metafunctional slice' with 'multistratal coverage': i.e. we consider a small extract of talk within a surgery setting from the perspective of Halliday's interpersonal metafunction. We then finish the paper by looking forward to the possibilities of (and constraints on) bringing this kind of multistratal approach into larger scale, computational accounts of register. 


\section{The concept of 'register', according to Halliday}

The development of the concept of register reflects a need to explain variation according to use, and arises from a concern with the importance of language in action. Halliday notes it was Reid (1956) who first used the term 'register' to capture the notion of 'text variety' (Halliday, 2007 [1975]: 181], although the idea of looking at the importance of situation on language was in use much earlier - for instance by proto-pragmatists such as Wegener (see Nerliche, 1990) who considered both the 'user' and 'use' in his concept of situation. Although it seems obvious that people speak differently in different situations, systematic analysis of variation according to what might be considered contextual features such as setting, addressee, subject and formality is relatively recent. Both Firth (1950) and Hymes (1969) developed accounts of the elements of context relevant to the act of speaking. The concept was developed by Ure (e.g. Ure, 1969; Ure and Ellis, 1972), and interpreted in Halliday et al. 2007 [1964: 181] 'within Hill's (1958) "institutional linguistic" framework' where the concepts of 'field', 'mode' and 'style of discourse' were introduced. Later, Halliday adopted the term 'tenor' from Spencer and Gregory (1964). Matthiessen et al's recent 'typology of registers' (e.g. 2008) draws directly on Ure's work. The notion of register has helped shape many approaches to language, including the Birmingham school (e.g. Sinclair and Coulthard, 1975) and corpus linguistics (e.g. Biber, 1995), although register is understood among these schools in markedly different ways. Halliday first made use of the term 'register' in a paper titled 'The users and uses of language.' ${ }^{2}$ In differentiating his approach from the general move of stating that language varies according to situation type, Halliday (1978: 32) suggests that what 'register does is to attempt to uncover the general principles which govern this variation, so that we can begin to understand what situational factors determine what linguistic features'.

Register is defined by Halliday as a semantic configuration (e.g. Halliday, 2002 [1977], 1985/89). As such, this stratal designation reveals something about both what Halliday means by register, and how Halliday conceptualizes the semantic stratum: register is a semantic phenomenon in the sense that 'register is the clustering of semantic features according to situation type' (Halliday, 1978: 68, 111, 123). As Figure 1 shows, the semantic stratum is, for Halliday, where language interfaces with the eco-social environment. At this interface, register is 'the necessary mediating concept that enables us to establish the continuity between a text and its sociosemiotic environment' (Halliday, 2002 [1977]: 58; see Bowcher, forthcoming). 


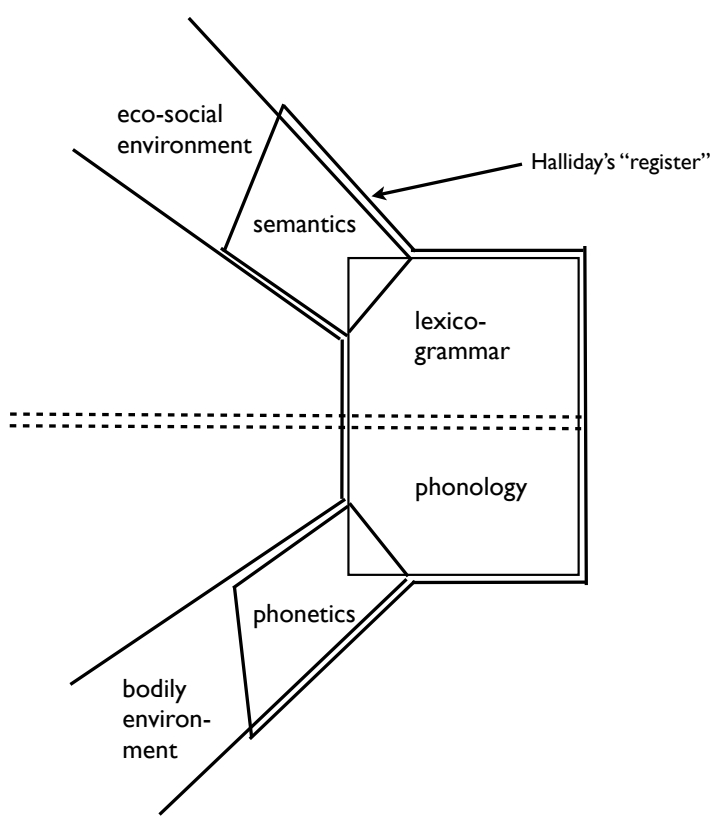

Figure 1: Language in relation to its bodily and eco-social environment (Reproduced from Halliday, 2003: 13)

\section{How 'register' in Halliday's view positions other concepts}

The choice of the definite article in Halliday's description of register as 'the mediating concept' implies that register has a central place in relating language to social context. It does so by virtue of its theoretical position in relation to the 'various assumptions about language' with which Halliday has worked over his career (2003: 1). In a recent paper, he notes that he did not start out from these assumptions, but rather that they 'emerged as the byproduct of those engagements [with language] as I struggled with particular problems' (Halliday, 2003: 1). Such assumptions have the status of theoretical categories; as such they 'are not subject to direct verification' (Halliday, 2003 [1992]: 201). These categories have a place in the theory by virtue of their descriptive power. They should not be 'endowed with a spurious reality of their own' (Halliday, 2003 [1992]: 200).

That language has 'stratificational complexity' (Halliday, 2003: 5) is one of these assumptions. As we have just noted, register is, from this perspective, located at the semantic stratum. Stratification implicates 'realizational complexity' (Halliday, 2003: 5). Thus, a 'setting of probabilities in the semantics', as 
Halliday has defined register, will mean certain selections and co-selections of features at the lexicogrammatical stratum, which in turn includes specifying some phonological features, since the realization of grammatical selections necessarily involves choices in intonation, in Halliday's account. Thus, while Halliday conceptualizes register as a configuration of meanings, he also shows register as cutting across all strata (Halliday, 2005 [1995]: 253ff). Halliday (2002 [1977]: 58) explicates the realization relation of register to context of situation as follows:

The patterns of determination that we find between the context of situation and the text are a general characteristic of the whole complex that is formed by a text and its environment. We shall not expect to be able to show that the options embodied in one or another particular sentence are determined by the field, tenor and mode of the situation. The principle is that each of these elements in the semiotic structure of the situation activates the corresponding component in the semantic system, creating in the process a semantic configuration, a group of favoured and foregrounded options from the total meaning potential that is typically associated with the situation type in question. This semantic configuration is what we understand by the register. (emphasis in original)

The implication is that (a) register is a function of all settings in the context, and that (b) it is in the activation by the contextual parameters of the corresponding components in the semantic system (the ideational, the interpersonal, and the textual metafunctions) that register comes into being. Given recent proposals about a rank scale in the semantics (Matthiessen, 1993: 23-31; Hasan, 1996; Cloran, 1994; Butt, 2003), we perhaps need to conceive of register as a higher order semantic configuration, realized in semantic units of various sizes, and potentially varying as registers vary (Matthiessen, 1993: 23-31); although proposals such as Halliday and Matthiessen (1999)'s 'figure', Matthiessen's (2004) system of RELATIONAL EXPANSION, Hasan's message semantics (e.g. 1996, 2009 [1992]), Cloran's Rhetorical Units (1994), and Butt's semantic cycles (2003), all claim to be generalizable across registers of any kind. Halliday (2005 [1995]: 255) argues that while we cannot as yet model the whole semantic system, we can 'specify its internal organization'. This, he suggests, is analogous to the function-rank matrix (see Table 1) but 'with its own distinct categories - a 'rank scale' of structural units such as, possibly, text, subtext, semantic paragraph, sequence, figure, element; and metafunctional regions defined in topological fashion, construing the activity patterns and ideological motifs of the culture (clusters relating to technology, to social hierarchy, to the sphere of activities of daily life, and so on)'.

The realization relation is bidirectional. Realization is a two-way relation (Halliday, 2002 [1992]; Hasan, 1995, 2010). As Hasan has recently noted: 
Realization works somewhat differently in the two directions. In the encoding view, it is an activation of some possible choice at the next lower level: thus in the production of an utterance, context activates meaning, meaning activates wording. By contrast, in the reception of the utterance, realization is construal of the relevant choice at the higher level: thus in decoding an utterance, the choice in wording construes meaning, the choice in meaning construes context. (Hasan, 2010: 12).

Halliday's function-rank matrix (see Table 1) is a detailed claim about the realizational relation between the stratum of lexicogrammar and that of the 'components' of the semantic system mentioned above. These components are the semantic analogue of the variables of the context (i.e. of field, tenor and mode). Thus, Halliday proposes there are meanings of the 'ideational', 'interpersonal' and 'textual' kinds; these components realize the features of the context, and in turn are realized by grammatical systems (in combination). The function/rank matrix is an hypothesis about (a) the proximity of lexicogrammatical systems within each metafunction; and (b) the relation of these systems to his assumption about the metafunctional organization of language.

The unit of text is the scale on which these systems configure. The text is an instance of a register, register itself being a midpoint along Halliday's 'cline of instantiation' (e.g. Halliday, 2002 [1992]). Halliday's cline resolved Saussure’s unnecessary bifurcation of langue and parole: 'langue and parole are simply different observational positions' (Halliday, 2005 [1995]: 248). As with stratification/realization relations, Halliday also accords the concept of register a central place with respect to the cline of instantiation:

I think that the critical intermediate concept, for our purposes, is that of register, which enables us to model contextual variation in language. Seen from the instantial end of the cline [of instantiation - authors], a register appears as a cluster of similar texts, a text type; whereas seen from the systemic end, a register appears as a subsystem. (Halliday, 2005 [1995]: 248)

We turn now to an illustration of this central concept being 'put to work'.

\section{Operationalizing register}

Given the key role the concept of register plays in describing the relationship of language to its eco-social environment from an SFL perspective, the capacity to operationalize the term must be a function of the state of play in modelling context. Hasan (2009a) argues that, like other strata, it is possible to model context paradigmatically, through the tool which has been used to model other strata, namely, the system network (Hasan, 1999, 2004, 2009a). She critiques standard SFL applications of the terms 'field', 'tenor' and 'mode' as vague, lacking 'checkable' criteria, and relying on 'common sense' (Hasan, 
Table 1: Function - Rank matrix (Halliday, 2009)

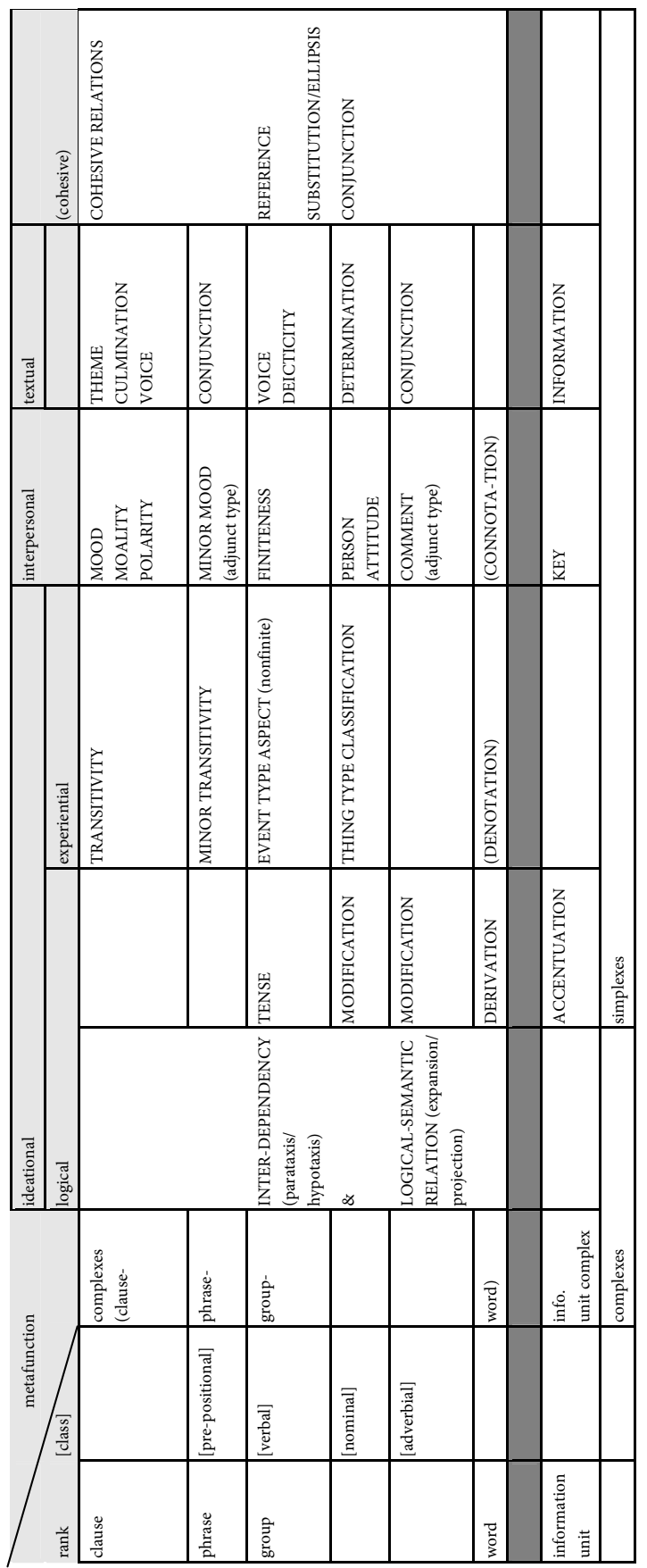


2009a: 179-180). System networks for contextualization remain 'at a nascent stage' (Hasan, 2009a: 181) but these 'contextualization systems have the distinction that instead of taxonomizing realized meanings, they actually systemize the realization-activating contextual features and attempt to relate context to wording via meaning, which acts as the interface between the two' (Hasan, 2009a: 181-182).

A related but distinct approach to operationalizing register can be seen in the way that Matthiessen and colleagues have pursued Halliday's goal of understanding 'what situational factors determine what linguistic features'. Drawing in particular on the work of Ure (1969), Matthiessen et al.'s development of a typology of registers is a move towards this understanding. The typology in its current form combines field (divided into 'semiotic processes' and 'social processes'; with 'semiotic processes' further specified as 'expounding', 'reporting', 'recreating', 'sharing', 'recommending', 'enabling' and 'exploring') with mode (with 'medium' specified as either 'spoken' or 'written' and 'turn' specified as either 'dialogic' or 'monologic'). The authors note the absence of tenor in this model, but argue that in 'the area of typology we discuss here, there is a strong association between field and tenor in certain respects' (Matthiessen et al., 2008: 190).

The typology of registers foregrounds a continuum between types of semiotic process. It builds complexity into the model by specifying a large array of contexts of language in use, showing where these uses interface with each other, and relating all this variation back to a central 'core' of variation, if you will. An important implication here is that the 'co-selection of options' across the metafunctions at context level is pre-ordained. In the network approach, complexity is built in a different way: it is the features which are specified and arrayed, not the configurations. From a theoretical perspective, the network approach depicts field, tenor and mode as essentially orthogonal ${ }^{3}$ variables, and although there is debate about the extent to which there is 'mutual prehension' (Hasan, 1999: 245) between metafunctions, in practice many plausible different co-selections are available, both within and across metafunctions

\section{Capturing register at work in surgery interaction - networks all the way down?}

In the pursuit of operationalizing register, one key challenge is finding principled ways of selecting and co-ordinating analyses, since a comprehensive account of all systems, strata and ranks is impossible for anything other than very small corpora and/or very small texts (Matthiessen, 1993). Hasan's and Butt's proposals for modelling context paradigmatically constitute a significant advance here, because they make it possible to conduct multistratal analyses 
by integrating network-based descriptions at the levels of context, semantics and lexicogrammar.

Our illustration in this section takes an 'interpersonal slice' (cf. Matthiessen's 'metafunctional slice', 1993: 276), and tests the possibility of calibrating Butt's tenor network $(2003)^{4}$ with Hasan's network for Commands (2009 [1992]) to model the context of surgical interaction (Matthiessen's 'metafunctional slice' with 'multistratal coverage'). We chose the interpersonal metafunction for our 'slice' because, first, it seemed to us that interpersonal 'situational factors' (tenor) in surgery teamwork bring a very particular kind of pressure to bear on the 'linguistic factors' observed in surgical interaction (after Halliday, 1978). In other words we expected that interpersonal choices and structures might constitute something like Halliday's 'prototypical syndrome of features' that characterize a register, for the context of surgical interaction. In particular, we were interested in those features through which team members enact, mitigate and negotiate control of each other's actions in a complex and highly repercussive environment. Our focus on speech function was a way of testing the plausibility of using semantic-level categories in register analysis, rather than skipping directly from the context directly to lexicogrammatical features, since Halliday suggests that register is brought into being when contextual features such as tenor activate 'the corresponding component in the semantic system. A further reason was that the system of SPEECH FUNCTION has been significantly developed in Hasan's work on message semantics, both with respect to delicacy and realization, as outlined below (see Hasan et al., 2007; Hasan, 2009b).

Data for our example are drawn from a project on 'Systemic Safety in Surgical Interaction' (Cartmill, et al., 2007; Moore et al., 2010; Moore, in press).5 This research constitutes an important element that had hitherto been missing from work on medical safety, which had almost entirely focused on identifying 'root causes' of adverse events, including 'communication factors' (e.g. Wilson et al., 1999). Very little attention had been given to the question of how it is that, in most cases, skilful surgical interaction (not just deft handiwork) manages risk and avoids error, on a day-to-day, minute-by-minute basis. As Hasan points out (2006: 40) 'linguistics has its work cut out for it: its job is to demystify the production of linguistic meanings', although we often need to mystify it first, since 'the world of meanings is experienced by social subjects as "already there". Our project undertook a map of such 'typical-actual' interaction in surgery. See also Smith (2008) and Moore (in press) for accounts of this material which build in analyses of body alignment, and intonation, respectively.

\section{The 'taking over' episode}

Turning now to the example data, Table 2 displays a transcript of talk between team members during colorectal surgery. The episode begins with growing 
tension about how quickly things are proceeding. Here the senior surgical trainee (the Registrar, with $10+$ years of medical training/experience) is doing the surgery. The Specialist (a professorial-level surgeon) is in a supervisory role, but is also 'assisting' the Registrar. The rising tension puts on notice (first implicitly then explicitly) the question of swapping roles, and having the specialist perform the operation. Although there is no space to discuss field or mode in detail, note that roles relating to both material action and pedagogical action are simultaneously activated, with their short and long-term goals, and their settings along the cline between constitutive and ancillary roles for language. These two kinds of action can be thought of as first order and second order field (Halliday, 2002 [1977]) and the tenor settings in our discussion relate to these two orders of field. An expanded discussion of the field of surgery practice - with its ubiquitous junior students, senior trainees and visiting observers - could also profitably refer to Bernstein's notion of pedagogic discourse, especially in terms of the relationship between instructional and regulative discourses (see e.g. Bernstein, 1996), and how these elements configure differently in surgery from the way they structure other pedagogic contexts (see e.g. Christie, 2000).

Table 2: Extract from surgical data - the 'taking over' episode

\begin{tabular}{|l|l|l|l|}
\hline Msg & Spkr & Text & SF \\
\hline 1 & S & Is it coming? & Q \\
\hline 2 & R & It is. Hmm. & S \\
\hline 3 & & Jenny, I'm just gonna move you in deeper & C \\
\hline 4 & & Grab that & C \\
\hline 5 & & er ah ((exerting considerable force) $)$ & - \\
\hline 6 & & there, just there ((sotto voce) $)$ & - \\
\hline 7 & & $(($ looks to up and out to middle distance $))$ & - \\
\hline 8 & & Oh no, yeah, I can feel it. & S \\
\hline 9 & S & Are your fingers down bel- below it? & Q \\
\hline 10 & R & Almost like a suction effect at the moment in the pelvis & S \\
\hline 11 & & My fingers are below it. & S \\
\hline 12 & S & Ok well pull on em hard. & C \\
\hline 13 & & Pull up on that band. & C \\
\hline 14 & & Nah this is & - \\
\hline 15 & R & Nup & - \\
\hline
\end{tabular}




\begin{tabular}{|c|c|c|c|}
\hline Msg & Spkr & Text & SF \\
\hline 16 & S & ... faffing, isn't it & Q \\
\hline 17 & $\mathrm{R}$ & It is faffing & $S$ \\
\hline 18 & S & Oh that's not the word, um. & S \\
\hline 19 & & It's all very stiff in there, just from his previous disease. & S \\
\hline 20 & & Let's just go straight down the middle of the front & C \\
\hline 21 & & and see what we run into. & C \\
\hline 22 & & Can you get a little small sponge thanks $\mathrm{N}$ or a medium sponge. & C \\
\hline 23 & & So we've just had a & S \\
\hline 24 & & roll it into a ball, into a roll, & C \\
\hline 25 & & so we've been frustrated & S \\
\hline 26 & & and weve been - what? - repelled (yep) & $S$ \\
\hline 27 & & so we're just gonna try another (way) & C \\
\hline 28 & & so just roll that down & C \\
\hline 29 & & that might be too much actually & S \\
\hline 30 & & and get down there, & C \\
\hline 31 & & pull on that bit & C \\
\hline 32 & & and i'll see if J and i can show you that & O \\
\hline 33 & & J can you - you help me & C \\
\hline 34 & & we'll both hold a second & C \\
\hline 35 & & you need to get more than one finger down there & C \\
\hline 36 & & so - so that you've got a little bit of a front & $S$ \\
\hline 37 & & And an angle ((12 secs silence $))$ & $S$ \\
\hline \multirow[t]{2}{*}{38} & & Let me move the retractor & C \\
\hline & & $((11$ messages omitted $))$ & \\
\hline 49 & $\mathrm{R}$ & Sorry, I'm in the way, aren't I? & Q \\
\hline 50 & S & No. & S \\
\hline 51 & & I just can't stand it any more & S \\
\hline 52 & $\mathrm{R}$ & I'm actually getting somewhere now & S \\
\hline 53 & S & No but you're doing - you're doing fine & $S$ \\
\hline 54 & $\mathrm{R}$ & You wanna take over, don't you. & Q \\
\hline 55 & S & No, no & S \\
\hline 56 & $\mathrm{R}$ & Yes you do & S \\
\hline
\end{tabular}




\begin{tabular}{|l|l|l|l|}
\hline Msg & Spkr & Text & SF \\
\hline 57 & S & No. I absolutely don't want to take over. & S \\
\hline 58 & R & You do, I feel. & S \\
\hline 59 & S & Well? No I don't, I don't & S \\
\hline 60 & R & I didn't say I was going to let you & S \\
\hline
\end{tabular}

Table note: In Column 2 the speaker is shown as S = Surgeon; R = Registrar; Message (after Hasan, 2009[1992], 1996) numbers are displayed in the left hand column. In the right hand the Speech Function of each message is shown as $\mathrm{Q}=$ Question; $\mathrm{S}=$ Statement; $\mathrm{C}=$ Command; $\mathrm{O}=\mathrm{Offer}$; messages which show no selection are punctuative messages (cf minor clauses). Shading indicates phases; the darkest shade indicates the earliest phase; the lightest indicates the latest phase (analysis of phase broadly follows Gregory e.g. 2002), discussed below in relation to variation in tenor.

How do the specialist and the senior trainee keep their complex and shifting roles in play, and manage the eventual handover without damage either to the patient, or to the quality of the pedagogic relationship which underpins surgical training programmes? The answer lies, in part, in the participants' mastery of registerial principles, particularly regarding the interpersonal function. In other words they are relating context to meaning via wording, and agreeing sufficiently about it to pursue an organized but changing joint activity (see Hasan, 2000). As the table above shows, Commands occur very frequently in this text (16/50 messages are Commands). Although they are not as frequent as Statements (there are 23 Statements, five Questions, one Offer and five punctuative messages) it would seem producing and 'hearing' Commands appropriately is a central plank of the team's expertise in relating context, meaning and wording, and that the need to be able to do so says something important about surgery as a social activity. In order to tease out and test this observation, we first identify some features from Butt's tenor network (see Figure 2). These features, we argue, have a central role in activating the observed selections in the interpersonal semantics, which will be described in the subsequent section (see Figure 3).

\section{Identifying the relevant parameters of tenor}

Before commenting on the tenor selections, a very brief word about Butt's model is in order. Whereas Halliday's original conception of tenor was 'the cluster of socially meaningful participant relationships, both permanent attributes ... and relationships that are specific to the situation, including the speech roles' (Halliday, 1978: 143) and his early tenor descriptions were labels such as 'doctor/patient' or 'parent/child', Hasan modelled tenor as three distinct features, namely AGENTIVE ROLE, SOCIAL HIERARCHY and SOCIAL DISTANCE (Hasan, 1979, 1985/89). Hasan's descriptions of SOCIAL 


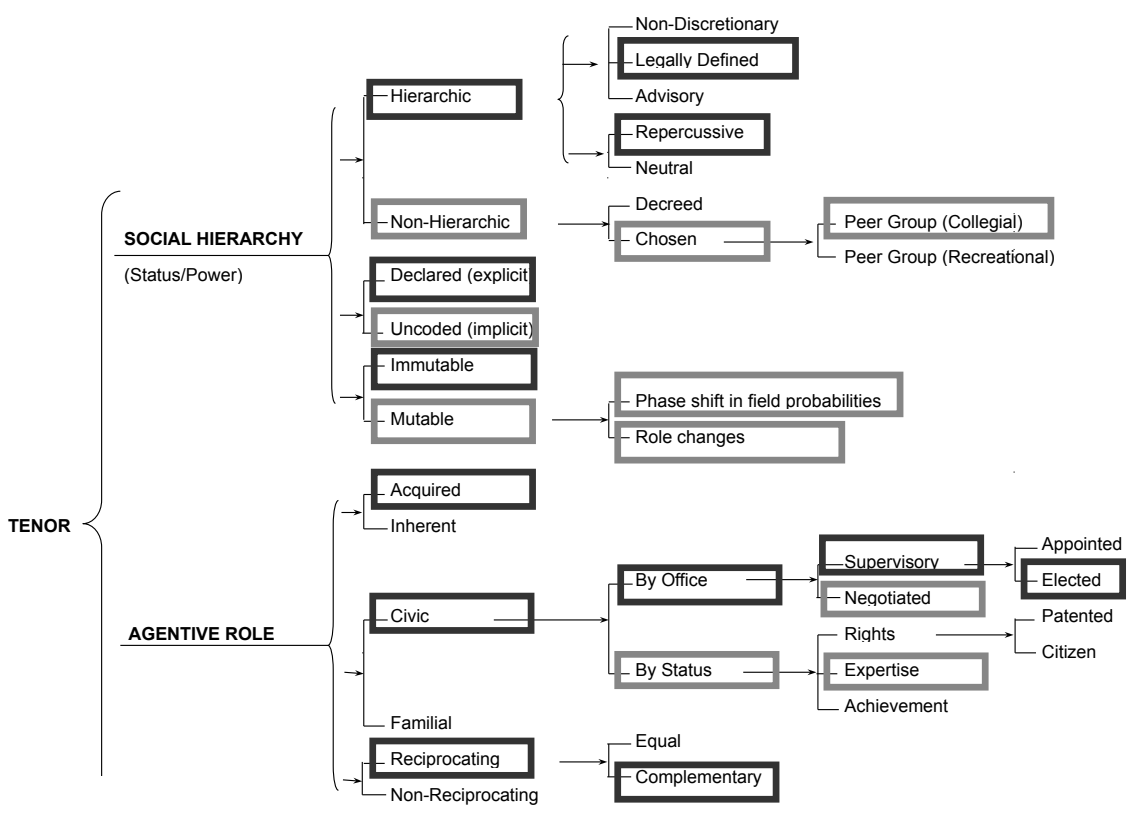

Figure 2: Selections in SOCIAL HIERARCHY and AGENTIVE ROLE in 'Taking over' text (After Butt, 2003. See note 7 for explanation of shaded boxes.)

DISTANCE and SOCIAL HIERARCHY became inherently comparative, although AGENTIVE ROLE remained similar to Halliday's 'label' approach (see Hasan, 1985/89). In Butt's (2003) model, tenor has been modelled as parallel systems in a network, and the contrasts are outlined and illustrated in Figure 2. ${ }^{6}$ The value of this approach is that potential contrasts between co-selections of field, tenor, and mode become numerous, and the analyst can map the character of a particular instance (or set of instances) as a particular configuration of choices across all these 'domains of contrast' and compare it against any other instance, broader dataset/corpus, or idealized variety. ${ }^{7}$

In the 'Taking over' episode above, the 'hot spots' in the network are arguably the dimensions of AGENTIVE ROLE and SOCIAL HIERARCHY. Within AGENTIVE ROLE, the instance above selects [reciprocating], ${ }^{8}$ since 'the relation is bi-directional, i.e. the participants/actants ... act on each other' (Butt, 2003: 15). That is, in order to teach/train/mentor the (surgical) teacher needs a (surgical) trainee; likewise the assistant surgeon role only exists with respect to a principal surgeon. Going further in delicacy within the choice of [reciprocating], this instance selects [complementary] rather 
than [equal] agentive roles, since the teacher's role and the learner's role are not the same. Compare this with the roles of, say, two debaters: the debaters have [reciprocal] roles, but the roles are [equal] (even though the quality of their arguments may not be!)

Within SOCIAL HIERARCHY, our instance selects [immutable] for teacher-student role, but [mutable] for the surgeon-assistant role relations. This can be seen in a change in actant status between the Specialist and the Registrar that finally occurs at message 91. The hierarchical differences are [declared] i.e. made explicit to all within the discourse community, by spatial and linguistic patterning. All of these selections (and more) are features of the 'relevant context' (Hasan, 2009a) because they motivate the kind of semiotic behaviour that occurs in the surgical instance and how it will be interpreted. In other words they activate and contextualize patterns on lower strata.

\section{Identifying 'activated selections' in the semantics}

We now turn to the semantic level descriptions. As outlined above, our passage has been analysed in terms of Hasan's network for Commands (Hasan, 2009[1992]; see also Hasan, 1996, 2006 for general discussions of semantic networks. The command network is part of a set of networks that covers the four speech functions, which Hasan called the system of ROLE ALLOCATION. See Hasan, 1996). Hasan's Command network extends the delicacy available for undertaking analyses of speech function. For our example of register analysis in surgery, we use only the first two 'levels of delicacy' within Command out of five levels of delicacy set out by Hasan, since significant patterning in the register in question occurs at this relatively indelicate level, according to our results. See Hasan (2009 [1992], 2009b) for (slightly different) versions of the full network.

The challenge for register techniques at this level of the analysis is to answer questions such as: What are the semantic options that are typically taken up in the register in question, under which contextual pressures and why? How do the semantic selections and co-selections construe the contextual configuration of surgery, in one instance, as it unfolds and shifts logogenetically? How do the semantic selections and co-selections of some members and some teams differ, and what does this indicate about their status, expertise and career potential? How do these selections assist us to understand and model what the situation demands? We cannot answer these questions in the scope of the paper, but for the purpose of illustration, we explore how the interpersonal semantic selection 'command', and the selection of specific types of commands, uttered by different members of the team, actively construes the complex and shifting tenor roles within the surgical team. 


\section{Speech function types as 'favoured and foregrounded' options}

Figure 3 displays both the systems of choice available once the features [demand] and [goods and services] which together construe the speech function 'command' are selected at message level, and the distribution of command types occurring in our example text. The shaded boxes indicate those grammatical features which realize the semantic options in the network, according to Hasan's model. Beside some options, small grey boxes show $S$ for Specialist or R for Registrar, indicating options taken up in at least one message, and by whom. The roman numerals in the grey boxes show in which phase of the episode the option is selected.

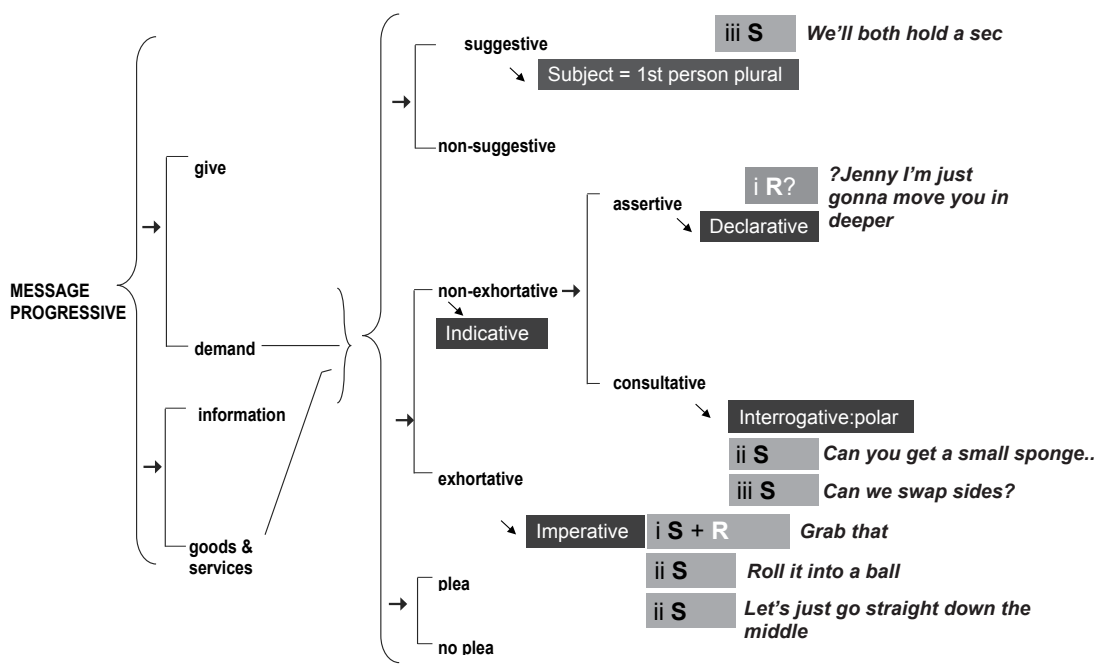

Figure 3: Semantic network for speech function 'Command', showing options taken up in the 'Taking over' episode (after Hasan, 2009 [1992]; some further options in delicacy not displayed).

As the network shows, a Command can have the semantic feature [suggestive], in which case it will be realized crucially (although not in isolation) by preselecting the first person plural as the Subject of the clause which realizes the Command as message. An example of a [suggestive] command from our data is We'll both hold a second. Another is Let's just go straight down the middle of the front. The contextual value of this semantic feature is that it presents the command as a directive, but construes the proposed activity as a joint enterprise. In the synoptic context of our example, a [suggestive] Command arguably serves to construe the tenor dimension of Agentive Roles as [recip- 
rocating]. From a more dynamic perspective, the [suggestive] command with its plural first person Subject can be seen as a way of holding the reciprocal role relations constant for now; it is a way of saying that the action needs to change but the agentive roles remain 'us as we are'. In contrast to [suggestive] commands, wherever the Subject of the clause realizing the command is second person, implied second person, or first person singular, the Command is said to be [non-suggestive]. An example would be Roll it into a ball. The contextual value of this choice [nonsuggestive; exhortative] is the construal of the command more as advice and possibly even criticism, and less as joint enterprise.

The other major 'cut' in Hasan's description of Commands which is relevant to our illustration is the choice between [exhortative] and [nonexhortative] commands, which basically follows the distinction at lexicogrammatical level between imperative and indicative mood respectively. Following on from that, there is an option for non-exhortative commands to be either [assertive] or [consultative], where [assertive] commands preselect declarative mood (with some further stipulations, such as modal Finite); and where [consultative] selects interrogative: polar as mood (but not interrogative more generally).

Not only does the first step into the system offer three sets of freely combinable options, two of these systems offer further delicacy of description, yielding quite an array of different interpersonal positionings in making a command Our example above of the command We'll both hold on a second is not only [suggestive] but also shows the feature [non-exhortative]. Within the feature [non-exhortative] two further options are opened up: [assertive] versus [consultative]. Our examples is an instance of the [assertive] type. On the other hand, a Command such as Can we swap sides? combines two 'softening' features, if you like - namely [consultative] and [suggestive]. Where commands are [non-suggestive] and [asssertive] a further distinction between addresseeoriented (You need to get more than one finger down there) and speaker-oriented (I'd like fresh gloves) applies, as realized by the choice of Subject person.

\section{Favoured semantic options construe tenor and phase}

Turning to the distribution of Command types within our example episode, Figure 3 shows that the Registrar uses a smaller number and variety of Commands than the Specialist. The Registrar uses Commands which are [exhortative; non-suggestive; non-consultative] e.g. Grab that. She also uses a form with the junior medical student for which Hasan does not appear to have a category, in Jenny, I'm just gonna move you in deeper, but which is clearly also [non-suggestive; non-consultative] (we come back to this further below). 
The Specialist's choice of Command type seems to be related to the phase of the episode, a point which recalls Firth's interest in the interaction of spoken language with the context of situation, and 'the way each moment both narrows down and opens up the options available at the next' (Halliday, 2005 [2002]: 178 ). When the context is relatively stable (phase 1: messages 1-14) the Specialist selects Commands with the features [non-suggestive; exhortative] e.g. Pull up on 'em hard, directed to the Registrar. As the contextual configuration becomes more unstable (message 15ff), the Surgeon's commands polarize into [assertive: addressee oriented] - You need to get more than one finger below it and, on the other hand, [consultative] and/or [suggestive] - Can we swap sides? In the moments when actants are carefully re-negotiating their roles, the specialist, in whom ultimate authority and responsibility resides, uses types of commands which treat the Registrar 'as if she has the right to demur' (Hasan, 2009 [1992]: 293). The Registrar does not use these kinds of Commands at all, and stops making Commands at phase 2. Our interpretation of the patterns shown in Figure 3 is that they are motivated, in part but very strongly, by the patterns displayed in Figure 2. In other words, the Contextual Configuration (but in particular the mutable, complex agentive relations identified above) appears to mediate message type and delicacy within type, by speaker and addressee. A fuller analysis displays other patterns which are coherent with these semantic tendencies (Moore, in press).

\section{Register expands meaning potential in several ways}

It is axiomatic in register studies that contextual settings constrain meaning potential and the episode presented here is no exception. Commands are arguably more frequent in this context than in English overall, or in many other contexts. In addition, the selection of options within the Command system is quite restricted, as Figure 3 suggests. However, it also seems that the phenomenon of register can, in some sense, expand the meaning potential of an instance (not just of the system of language overall, as Matthiessen (1993) cogently argues) since the set of lexicogrammatical features which count as realizing a command appears to be expanded by the contextual configuration here.

Our evidence for this claim is that in Message 3 we saw that I'm just gonna move you in deeper is construed as a Command. ${ }^{9}$ Messages realized by declarative clauses are normally construed as Statements unless they have either second person Subject plus modal Finite (You need to move in deeper), or the speaker is construed as first person Senser in a projecting alpha-clause, with second person Subject/Actor in the beta-clause (I'd like/I want you to move in deeper). In our example, instead, the speaker is first person Subject/Actor in a 
Material Clause with Addressee as Goal. However, it is not difficult to supply the semantic analogy between these grammatical configurations, since each implies the speaker's preference regarding the addressee's state or envisaged action.

Arguably then, the contextual configuration(s) of surgery predispose participants to interpreting messages as Commands: in other words it is harder in surgery than in other contexts to hear a message as anything other than a Command, and there is more semiotic material available for making and varying Commands. This point illustrates Halliday's claim, noted earlier, that one of the reasons grammatical choices may mean differently is the probabilities of such choices in the general system, versus their take up in a given register. Note also that in identifying this message as a Command we are, as always, shunting between the view from 'below' (citing a lexicogrammatical realization that is agnate to more typical realizations of Commands); the view from 'above' (noting that the configuration of agentive roles, goals, and types of action increases the probability of Commands occurring); and the view from 'round about' where, among other things, we form and test our categories by considering the likely response to such utterances: if Jenny doesn't move in, we would predict a repeated or perhaps a more congruent wording of the Command.

\section{Challenges and prospects in register analysis}

Before closing this example, there are a number of shortcomings and challenges we will pursue at length elsewhere but want to mention here. First we want to forestall some possible misinterpretations from our pragmatic use of one incomplete text analysis. Presenting only tenor and interpersonal semantics does not mean that a full register analysis could be done without considering experiential or textual patterning. It is also important to note that although we value the 'slice' through one metafunction as an efficient way of providing a multistratal view, it is not our view that only interpersonal systems in the grammar or semantics are involved in realizing interpersonal values in higher strata, or that interpersonal features such as mood, modality, speech function and others (tense, polarity, etc.) are never involved in construing field and mode (see Hasan, 1995, on this point). Providing only one small text (segment) should also be taken within the context of our purpose in this paper. Our explication of this text is presented by way of illustrating the ways in which we feel the analytical categories of context, semantics, lexicogrammar (and intonation) need to be made to speak to each other. The relations we have posited between the contextual features of tenor and the semantic features of speech function seem plausible for our text. But our claims can only 
have a tentative status until they can be tested across many more instances, and more registers.

A workable quantitative framework is sorely needed for testing questions such as whether there is a consistent relationship between the contextual parameters and the semantic parameters we found in the 'Taking over' episode. At the moment, register studies are still divided, in our view, between approaches which prioritize complex models of language but can't quantitatively test their hypotheses yet (like the work displayed here), and those which prioritize sampling strategies and automated coding and therefore can only handle more parsimonious models of language, although computational register profiles based on co-selection of lexicogrammatical categories are gaining ground. As information is assembled, combined and compared across registers, and across quantitative and manual approaches to register, it becomes more plausible to make a representative sample of English that appropriately encompasses variation at the strata and ranks of interest, rather than attending quantitatively only to crude indices of the variables that matter (see e.g. Teich (2003) for discussions of these issues, and Halliday (2005 [2002])).

Looking further out, to register typology, a quantitative framework is also needed for answering questions about the extent to which contextual configurations like those in surgery apply the same pressure on interpersonal semantics as other 'apprenticing' contexts that share a similar complex material and pedagogical field, along with similar tenor. Would our surgery context prove to be a different register from mentoring a motor mechanic, if we take unique stratal alignments between context, semantics and wording to be the measure of 'a' register? Perhaps the particularly repercussive nature of surgical work, along with the kind of cultural capital, time investment, and eventual collegiality (but also the professional/institutional allegiances and clefts between medical, nursing and other groups) that are involved in becoming a surgeon, all work together to make it necessary or functional for members to have a complex repertoire of conveying instructions to each other in surgery that is not as elaborated in 'blue collar' industries. The most important thing to note here is that this is an empirical question. It is impossible to test claims about consistent relations between register and other discourse categories if register is treated as a 'natural kind' that corresponds to folk categories of situation, which is why a parametric approach at all levels holds considerable promise, despite the challenges.

\section{Concluding remarks}

Putting concepts such as register to work is crucial to developing the concept, since 'theory and description develop in interaction' (Matthiessen, 1993: 224), and the challenges that arise through description, as we have seen 
above, feed into the further development of theory and hence into future methods for application. The meaning of the variations seen above can only be interpreted by reference to the context of a situation; and the variation selected by register can only be understood with reference to system potential. This fact underlies Matthiessen's (1993) call for a 'two-pronged approach' to register studies.

Just as we can look at context in 'variable degrees of delicacy so we can give whole families, subfamilies or single registers contextual values depending on the degree of delicacy we select within context' (Matthiessen, 1993: 236), so it might be possible to give contextual variables from the perspective of different individuals, groups of individuals or even technology. This is particularly important when using the context networks as outlined by Hasan (1999) and Butt (2003).

Despite the challenges inherent in register studies, in this paper we have illustrated something of the theoretical and instrumental value of Halliday's notion of register. One of the values of the notion is that we do not have to describe everything or deal with the full complexity of the culture. This does not mean that we do not keep the culture in mind. Any picture of a part of the system necessarily has the full system behind it. Register is perhaps best understood as a dialectic - between system and instance - since the two are never actually possible without each other. It does not so much sit between system and instance, as it is a take on system and instance at the one time. It is the culture brought to bear on the instance of the social process. This means that we are not faced with the unhelpful uniqueness of each instance, because we are viewing it through the system and therefore foregrounding the shared aspects. Neither are we confronted with the seemingly impossible task of transcribing the infinity of culture because we are viewing the culture through the aperture of the instance. The robustness of Halliday's account of register - robust in the sense that the term's relation to each other term in the theory is explicit - resolves the problem for linguists (as set out in Halliday, 2003) of 'the nature of a semiotic fact'. It does so by creating a means of bridging the gap between theory and observation.

\section{Notes}

1. Martin has sometimes downplayed the distinction between his and Halliday's model. He suggests in English Text that 'there is nothing substantive' in the distinctions between claims about the realization of text structure in his and Hasan's models (1992: 505), although in other places he highlights specific differences - see e.g. his point about 'rejecting [Halliday's] association of genre with mode' (Martin 1999: 31) and foregrounds the opportunities for an expanding 'metatheoretical space'. By the same token a recent paper by Martin (2009) identifies Halliday's model of social context as having 'led to the development of genre analysis, particularly in Australia' (2009: 154). The claim is referenced in relation to both his and Hasan's 
work - implying that the term 'genre' by the two scholars can be essentially equated. Further evidence for our claim that Halliday's conceptualization of register has been obscured can be found in Bateman's recent work on multimodality and genre, in which he claims that Hasan's early work shows 'clearly' the view of genre as "staged, goal-oriented social processes" that has subsequently become a cornerstone of approaches to genre in general' (Bateman, 2008: 186). His history of work on genre includes reference to 'the final move to genre within the SFL account' (2008: 184), made on the basis, according to Bateman, of the problematic "homogeneneous" view of text' which register apparently offers, a view that he suggests is countered by bringing in Martin's notion of 'genre'. It is worth noting here that Halliday has not adopted Martin's alternative proposal.

2. This paper was published with McIntosh and Stevens, but it was in the main written by Halliday - see footnote to the paper, published in Language and Society, Volume 10 on Halliday's Collected Works. 2007 [1964]: 37.

3. By orthogonal here we mean that the primary systems field, tenor and mode (and to a lesser extent the domains of contrast within each) are considered to be potentially independent or uncorrelated. Hasan $(1995,1999)$ discusses the type and degree of interdependence that appears to exist between different contextual features, and their relation to register; more discussion is needed in our view. However, one benefit of an 'orthogonal' network approach is that it can reveal historical and cultural differences in which contextual features can co-occur in a culture, and which configurations construe 'non-contexts'.

4. Butt's mimeo on 'Parameters of Context' includes field, tenor and mode networks which have been adapted and extended from Hasan's expanded network for Field (Hasan, 1999) and her earlier work on these parameters.

5. This project was supported by an ARC Discovery Project, CIs D. G. Butt and J. M. Cartmill, named A. P. A. Moore. Data included 60 hours of videotaped routine surgical interaction.

6. Hasan's three tenor features were refashioned in Butt (2003) into three interacting, parallel systems in a network, working along similar lines to Hasan's model (1999) for Field, with an additional fourth system, Network Morphology, as a way of bringing social networks into the Tenor frame, giving approximately 100 selectable features just for tenor. A better indication of how much territory is encompassed by these networks may be a measure of 'degrees of freedom' but it is difficult to ascertain these in a hierarchical model, e.g. it is not clear whether the most delicate options should have the same weight as 'earlier' nodes in the network.

7. Additional delicacy can be built in by the analyst, and multiple passes through the system are 'allowed'. In the Tenor diagram, the grey boxing shows a first pass which relates primarily to the institutional demands of the context of situation (complementarity of roles in the operating suite, the [declared; immutable; hierarchical] status of professor to a junior staff member/trainee, etc. The paler grey boxing indicates a second pass through the system, showing choices that pertain to the emerging professional solidarity between the two primary interactions as colorectal surgeons (e.g. emerging mutability of the hierarchy, collegial basis of the hierarchy, etc.).

8. The square brackets denote this term is a selection from a system network.

9. This is treated as a Command because in response to this utterance, Jenny adjusts her posture and utters a compliance token ' $\mathrm{mm}-\mathrm{hmm}$ '. The alternative view would be to treat 'I'll move you in' as a Statement, and the 'mm-hmm' alone could of course realize merely an acknowledgement in a statement, so this token does not in itself count as evidence of a response to a command. Jenny does not wait to be adjusted but responds as one would expect a student to respond to a command, by performing the action represented. This, plus our expectation of disruption were the student to treat the registrar's utterance unequivocally as 
a Statement, pushes us towards interpreting it as a Command. Of course speech functions, as instances, often remain fuzzily interpreted without disrupting discourse flow - see e.g. Matthiessen et al. (2005).

\section{About the authors}

Annabelle Lukin is Research Fellow and Senior Lecturer in the Centre for Language in Social Life, in the Department of Linguistics at Macquarie University. Email: annabelle.lukin@ling.mq.edu.au

Dr Alison Moore is Lecturer in the Language Centre, at Wollongong University, and Associate of the Centre for Language in Social Life, in the Department of Linguistics at Macquarie University.

Dr Maria Couchman is Associate Lecturer with the Centre for Language in Social Life, in the Department of Linguistics at Macquarie University.

Rebekah Wegener is a Ph.D. candidate in the Centre for Language in Social Life, in the Department of Linguistics at Macquarie University.

Dr Canzhong Wu is Senior Lecturer with the Centre for Language in Social Life, in the Department of Linguistics at Macquarie University.

\section{References}

Bateman, J. (2008) Multimodality and Genre: A Foundation for the Systematic Analysis of Multimodal Documents. London: Palgrave Macmillan.

Bernstein, B. (1996) Pedagogy, Symbolic Control and Identity: Theory, Research, Critique. London and Washington DC: Taylor and Francis.

Biber, D. (1995) Dimensions of Register Variation. Cambridge: Cambridge University Press. doi:10.1017/CBO9780511519871

Bowcher, W. (forthcoming) The history and theoretical development of context of situation in Systemic Functional Linguistics. In C. Chang (ed.) Functional Studies of Context. Beijing: Foreign Language Teaching and Research Press.

Butt, D. G. (2003) Parameters of Context: On Establishing the Similarities and Differences Between Contexts. Unpublished monograph, Macquarie University.

Cartmill, J. A., Moore, A. R., Butt, D. G. and Squire, L. (2007) Surgical teamwork: Systemic Functional Linguistics and the analysis of verbal and non-verbal meaning in surgery. ANZ Journal of Surgery 77 (S1): A103-A108. doi:10.1111/j.1445-2197.2007.04129_10.x

Christie, F. (2000) The language of classroom interaction and learning. In L. Unsworth (ed.) Researching Language in Schools and Communities, 184-203. London: Cassell.

Cloran, C. (1994) Rhetorical Units and Decontextualisation: An Enquiry into some Relations 
of Context, Meaning and Grammar. Monographs in Systemic Linguistics, No. 6. Nottingham: School of English Studies, Nottingham University.

Firth, J. R. (1950) Personality and language in society. Reprinted in J. R. Firth Papers in Linguistics 1934-1951. London: Oxford University Press, 1959.

Gregory, M. (2002) Phasal analysis within communication linguistics: two contrastive discourses. In P. Fries, M. Cummings, D. Lockwood and W. Sprueill (eds) Relations and Functions within and around Language, 316-345. London: Continuum.

Halliday, M. A. K. (1978) Language as a Social Semiotic: The Social Interpretation of Language and Meaning. London: Edward Arnold.

Halliday, M. A. K. (1985/89) Part A. In M. A. K. Halliday and R. Hasan, Language, Context, and Text: Aspects of Language in a Social-Semiotic Perspective. Oxford/Geelong: OUP/ Deakin University Press.

Halliday, M. A. K. (2002 [1977]) Text as semantic choice in social contexts. In J. J. Webster (ed.) Linguistic Studies of Text and Discourse. Volume 2 in the Collected Works of M. A. K. Halliday, 23-81. London and New York: Continuum.

Halliday, M. A. K. (2002 [1988]) On the ineffability of grammatical categories. In J. J. Webster (ed.) On Grammar. Volume 1 in Collected Works of M. A. K. Halliday, 291-322. London and New York: Continuum.

Halliday, M. A. K. ([2002] 1992) How do you mean? In J. J. Webster (ed.) On Grammar. Volume 1 in Collected Works of M. A. K. Halliday, 352-368. London and New York: Continuum.

Halliday, M. A. K. (2003[1992]) Systemic grammar and the concept of a 'science of language'. In J. J. Webster (ed.) On Language and Linguistics. Volume 3 in Collected Works of M. A. K. Halliday, 199-212. London and New York: Continuum.

Halliday, M. A. K. (2003) Introduction: On the 'architecture' of human language. In J. J. Webster (ed.) On Linguistics and Language. Volume 3 in Collected Works of M. A. K. Halliday, 1-29. London and New York: Continuum.

Halliday, M. A. K. (2005 [1995]) Computing meanings: Some reflections on past experience and present prospects. In J. J. Webster (ed.) Computational and Quantitative Studies. Volume 6 in the Collected Works of M. A. K. Halliday, 239-267. London and New York: Continuum.

Halliday, M. A. K. (2005 [2002]) The spoken language corpus: A foundation for grammatical theory. In J. J. Webster (ed.) Computational and Quantitative Studies. Volume 6 in the Collected Works of M. A. K. Halliday, 157-189. London and New York: Continuum.

Halliday, M. A. K. (2007 [1975]) Language as social semiotic. In J. J. Webster (ed.) Language and Society. Volume 10 in the Collected Works of M. A. K. Halliday, 169-201. London and New York: Continuum.

Halliday, M. A. K. (2009) Methods - techniques - problems. In M. A. K. Halliday and J. J. Webster (eds) Continuum Companion to Systemic Functional Linguistics, 59-86. London and New York: Continuum. 
Halliday, M. A. K. and Matthiessen, C. M. I. M. (1999) Construing Experience through Meaning: A Language Based Approach to Cognition. London, New York: Cassell.

Halliday, M. A. K., McIntosh, A. and Stevens, P. (2007 [1964]) The users and uses of language. In Webster, J. J. (ed.) Language and Society. Volume 10 in the Collected Works of M. A. K. Halliday, 5-37. London and New York: Continuum.

Hasan, R. (1979) On the notion of text. In J. Petöfi (ed.) Text Versus Sentence: Basic Questions of Text Linguistics. Papers in Text Linguistics 20. Hamburg: Buske. Cited in Hasan (1999).

Hasan, R. (1985/89) Part B. Language, Context, and Text: Aspects of Language in a Socialsemiotic Perspective. Oxford/Geelong: OUP/Deakin University Press.

Hasan, R. (1995) The conception of context in text. In P. H. Fries and M. J. Gregory (eds) Discourse in Society: Systemic Functional Perspectives. Meaning and Choice in Language: Studies for Michael Halliday, 183-283. Advances in Discourse Processes Vol. L. Norwood, NJ: Ablex.

Hasan, R. (1996) Semantic networks: a tool for the analysis of meaning. In C. Cloran, D. Butt and G. Williams (eds) Ways of Saying, Ways of Meaning: Selected Papers of Ruqaiya Hasan, 104-130. London: Cassell.

Hasan, R. (1999) Speaking with reference to context. In M. Ghadessy (ed.) Text and Context in Functional Linguistics: Systemic Perspectives, 219-328. Amsterdam: John Benjamins.

Hasan, R. (2000) The uses of talk. In S. Sarangi and M. Coulthard (eds) Discourse and Social Life. Edinburgh Gate: Pearson Educational.

Hasan, R. (2004) Analysing discursive variation. In L. Young and C. Harrison (eds) Systemic Functional Linguistics and Critical Discourse Analysis: Studies in Social Change, 15-52. London and New York: Continuum.

Hasan, R. (2006) Introduction: a working model of language. In R. Hasan, C. M. I. M. Matthiessen and J. J. Webster (eds) Continuing Discourse on Language: A Functional Perspective Vol. 1, 37-52. London: Equinox.

Hasan, R. (2009 [1992]) Meaning in Sociolinguistic Theory. In J. J. Webster (ed.) Semantic Variation: Meaning in Society and in Sociolinguistics. Volume 2 in the Collected Works of Ruqaiya Hasan. London: Equinox.

Hasan, R. (2009a) The place of context in a Systemic Functional Model. In M. A. K. Halliday and J. J. Webster (eds) Continuum Companion to Systemic Functional Linguistics, 166-189. London and New York: Continuum.

Hasan, R. (2009b) Semantic Variation: Meaning in Society and in Sociolinguistics. The Collected Works of Ruqaiya Hasan Vol. 2. Edited by J. J. Webster. London: Equinox.

Hasan, R. (2010) The meaning of 'not' is not in 'not'. In A. Mahboob and N. Knight (eds) Appliable Linguistics, 267-306. London and New York: Continuum.

Hasan, R., Cloran, C., Williams, G. and Lukin, A. (2007) Semantic networks: The description of linguistic meaning in SFL. In R. Hasan, C. M. I. M. Matthiessen and J. J. Webster (eds) Continuing Discourse on Language: A Functional Perspective Vol. 2, 297-738. London: Equinox. 
Hymes, D. H. (1969) Linguistic theory and the functions of speech. In International Days of Sociolinguistics (no editor). Rome: Luigi Sturzo Institute.

Martin, J. R. (1992) English Text: System and Structure. Amsterdam: John Benjamins.

Martin, J. R. (1999) Modelling context: a crooked path of progress in contextual linguistics. In Mohsen Ghadessy (ed.) Text and Context in Functional Linguistics, 25-61. Amsterdam: John Benjamins.

Martin, J. R. (2009) Discourse Studies. In M. A. K. Halliday and J. J. Webster (eds) Continuum Companion to Systemic Functional Linguistics, 154-165. London and New York: Continuum.

Matthiessen, C. M. I. M. (1993) Register in the round: diversity in a unified theory of register analysis. In Mohsen Ghadessy (ed.) Register Analysis: Theory and Practice. London: Pinter.

Matthiessen, C. M. I. M. (2004) The Semantic System of RELATIONAL EXPANSION: Rhetorical Structure Theory Revised. Unpublished manuscript. Department of Linguistics, Macquarie University, Sydney, Australia.

Matthiessen, C. M. I. M., Teruya, K. and Wu, C. (2008) Multilingual studies as a multidimensional space of interconnected language studies. In J. J. Webster (ed.) Meaning in Context: Implementing Intelligent Applications of Language Studies, 146-220. London and New York: Continuum.

Matthiessen, C. M. I. M., Lukin, A., Butt, D., Clereigh, C. and Nesbitt, C. (2005) A case study of multistratal analysis. Australian Review of Applied Linguistics. Series S (19): 123-150.

Moore, A. (in press) Surgical teams in action: a contextually sensitive approach to modelling body alignment and interpersonal engagement. In A. Baldry and E. Montagna (eds) Interdisciplinary Perspectives on Multimodality: Theory and Practice. Campobasso, Italy: Palladino.

Moore, A., Butt, D. G., Cartmill, J. and Ellis-Clarke, J. (2010) Linguistic analysis of verbal and non-verbal communication in the operating room. ANZ Journal of Surgery. Online version 21 Oct. 2010 doi: 10.1111/j.1445-2197.2010.05531.x

Nerliche, B. (1990) Change in Language: Whitney, Bréal, Wegener. London: Routledge.

Reid, T. B. W. (1956) Linguistics, structuralism, philology. Archivum Linguisticum 8.

Sinclair, J. and Coulthard, M. (1975) Towards an Analysis of Discourse. Oxford: Oxford University Press.

Smith, B. A. (2008) Intonational Systems and Register: A Multidimensional Exploration. Unpublished PhD thesis. Macquarie University.

Spencer, J. and Gregory, M. (1964) An approach to the study of style. In N. Enkvist, Spencer, J. and Gregory, M. Linguistics and Style. London: Oxford University Press.

Teich, E. (2003) Cross-Linguistic Variation in System and Text. A Methodology for the Investigation of Translations and Comparable Texts. Berlin, New York: Mouton de Gruyter. 
Ure, J. (1969) Practical Registers (Parts I and 2). English. Language Teaching, Volume XXIII, Number 2. Oxford University Press.

Ure, J. and Ellis, J. (1972) Register in descriptive linguistics and linguistic sociology. In Oscare Uribe Villegas (ed.) Las concepciones y problemas actuales do la sociolingüística. Mexico: University of Mexico Press.

Wilson, R. M., Harrison, B. T., Gibberd, R. W. and Hamilton, J. D. (1999) An analysis of the causes of adverse events from the Quality in Australian Health Care Study. Medical Journal of Australia 170: 411-415. 
Copyright of Linguistics \& the Human Sciences is the property of Equinox Publishing Group and its content may not be copied or emailed to multiple sites or posted to a listserv without the copyright holder's express written permission. However, users may print, download, or email articles for individual use. 